\title{
Tecnología y Transparencia
}

\author{
Iago Ramos ${ }^{1}$ \\ Elías Fuentes Guillén ${ }^{2}$
}

\begin{abstract}
Resumen: La concepción del ser humano como animal tecnológico, junto con la idea del progreso como sustento de la civilización, plantea varias cuestiones que precisan ser consideradas con detenimiento, entre ellas qué se entiende por progreso y qué sentido y valor tiene la tecnología. El caso de la realidad virtual (VR, acrónimo de virtual reality) patentiza de hecho la habitual asunción de la tecnología como algo ajeno a la producción cultural, humana. Sin embargo, la tecnología comparte nuestros límites y está sometida a nuestro designio, por más que se le quiera asumir independiente de nosotros y por más que se intente reemplazar nuestra interacción con el espacio natural por una relación enteramente controlada en un medio virtual.
\end{abstract}

Palabras Clave: Sociedad. Tecnología. Transparencia. Usuario.

\section{Introducción: Tecnología y Progreso}

En La sociedad primitiva (1975), Lewis Henry Morgan define la civilización como el periodo de la humanidad que va desde la invención del alfabeto fonético y el uso de la escritura, hasta el tiempo presente. La civilización, sin embargo, no sería posible sin un proceso previo que comienza en un estadio inferior de salvajismo [sic.], en el cual el ser humano no es más que un animal frugívoro que, a través del desarrollo de técnicas de pesca o del dominio del fuego, progresa hacia un estadio superior. De salvajes a bárbaros y de la barbarie a la civilización, el estado presente de la humanidad culmina un proceso exitoso que la teoría antropológica explica a través de la adquisición de técnicas cada vez más civilizadas. Al observar que, para Morgan, la escritura es civilizadora, pero no lo son otras técnicas que también requieren transmisión

1 Profesor de Filosofía en la Universidad de Salamanca, Salamanca - España. (D) http://orcid. org/0000-0003-4125-8086. E-mail: iago.ramos@usal.es

2 Investigador postdoctoral en la Universidad Nacional Autonóma de México (UNAM), Ciudad de México - México. (D) http://orcid.org/0000-0001-8722-5090 E-mail: eliasfuentesguillen@gmail.com

http://dx.doi.org/10.1590/0101-3173.2020.v43n1.05.p77

This is an open-access article distributed under the terms of the Creative Commons Attribution License. 
de información y organización social, como por ejemplo muchas técnicas de caza, podemos identificar perfectamente el contexto del autor y ese momento ideológico en el que la civilización se confunde con la alta cultura. Sería interesante poder trasladar a ese autor del XIX a una época como la actual, en la que la inocencia sobre los discursos públicos es menor, teniendo presente el uso de la escritura para llevar acabo masacres durante las dos guerras mundiales del XX. Hoy que sabemos que el carácter civilizador de la escritura también permite deshumanizar, ¿la seguiría utilizando Morgan como hito fundador de la civilización?

Para empezar, cabe considerar que Morgan sólo busca una referencia generalizable para clasificar el estadio en el que se encuentran diferentes sociedades, por lo que es muy posible que hoy acudiese a un parámetro distinto. La escritura como punto de división entre prehistoria e historia funciona muy bien porque la división se genera, precisamente, de manera relativa a la escritura misma. En el caso de la división que propone Morgan, es normal que cualquier medida que se proponga se vea superada por el desarrollo de nuestros conocimientos sobre sociedades pasadas y presentes. Así, el valor más objetivo que posee la caracterización de Morgan es que ilustra los prejuicios de su contexto respecto a los elementos que conforman la cultura, a la vez que ilustra una estructura respecto la relación entre lo humano y lo natural que todavía es mayoritaria en el mundo occidental. La conciencia pública presente, y muchas teorías antropológicas mantienen ese mismo esquema, en el cual los cambios en la humanidad se identifican con progreso respecto a un estado anterior de animalidad desde una perspectiva platónica de la realidad: un primer uso de objetos que nos permiten extender nuestras "habilidades naturales" abre camino hacia el desarrollo de un aparato teórico que nos permite dominar toda la naturaleza, empezando por nuestra propia naturaleza incivilizada. Dicho esquema está presente en nuestra conciencia pública de manera clara a través de ideas tan populares como que "la ciencia es conocimiento" y "la tecnología es aplicación de la ciencia". Lo cual, cabe mencionar, forma parte de manera transversal y más o menos subliminal de la mayoría de los currículums educativos europeos, siendo un esquema peligroso puesto que asume la transformación del ser humano, desde el salvajismo hacia un estado mejor, sin evaluar objetivamente si los cambios tecnológicos son positivos. Sabemos, por lo tanto, que hay progreso porque prejuiciosamente afirmamos que lo anterior era peor. 
La alta estima que se tiene del ser humano como animal tecnológico y de la civilización como progreso lleva a autores como De Waal a etiquetarse como proscritos y a que argumentos como los de Michael Tomasello en Por qué cooperamos (2009) sean puestos en duda: la posibilidad de que haya elementos fisiológicos en nosotros que nos llevan hacia la cooperación va contra la visión totémica de la civilización como espacio de salvación. La posibilidad de que pueda existir un altruismo individual (TOMASELLO, 2009, p. 51ss.) o, dicho de otra manera, que un salvaje pueda sacrificarse por un bien común en un estadio previo a la existencia de una espacio moral, producido por el progreso de la especie, se considera como un planteamiento nostálgico e idílico porque va en contra de nuestra visión de lo natural como un espacio incivilizado dominado por la barbarie. Da igual que la idea se plantee desde una base científica, esto es, que sea el producto más excelso de nuestra civilización el que proponga una revisión de nuestros prejuicios sobre la conducta individual: la idea choca con nuestras creencias básicas y necesitamos rechazarla.

Sin embargo, que el propio individuo pueda actuar de manera altruista no es una idea chocante dentro de los planteamientos de JeanJacques Rousseau, en los que el origen de la sociedad se articula a partir del reconocimiento mutuo entre dos individuos. De este modo, en el Ensayo sobre el origen de las lenguas (1995), Rousseau parte de la premisa de que la palabra es lo que distingue al ser humano del animal y afirma que se trata de la primera institución social tras el reconocimiento entre dos miembros de la misma especie (ROUSSEAU, 1995, p. 375). En su disertación, Rousseau reconoce que también los animales saben comunicarse entre sí, por lo que explicar la diferencia que introduce la palabra entre el ser humano y el animal requiere explicar cómo se produce la comunicación humana con las características que le son propias; a saber, que ella no atiende solo a una interacción de nuestro cuerpo con los eventos y objetos de la naturaleza, sino que crea un espacio moral a partir de nuestra experiencia del mundo ajeno a la necesidad natural. De este modo, frente al animal, nuestro lenguaje nos permite posicionarnos respecto de las cosas y apropiarnos del mundo natural, dando lugar a lo que, dentro del vocabulario rousseauista, se conoce como "segunda naturaleza". Un espacio en el que no surge la civilización como hito de excelencia cultural, sino que es el espacio de comunicación y organización gobernado exclusivamente por lo humano: "El lenguaje convencional no pertenece más que al hombre. Es así por lo que el hombre hace progresos, sea para bien o para mal, y por lo que el animal no hace ninguno." (ROUSSEAU, 1995, p. 379). 
En el esquema rousseauista, la tecnología no está vinculada con el progreso porque su función es transformar el mundo que habitan los seres humanos, generando con ello un espacio diferente y particular. Así, la tecnología y las técnicas no se diferencian de la naturaleza del ser humano, no son elementos ajenos con una función liberadora, sino que son elementos que conforman la segunda naturaleza en la que aquél está confinado de manera inevitable una vez que se ha convertido en un ente social. En cambio, el esquema hobbesiano de un ser humano que encuentra su salvación en la sociedad, pone sus esperanzas indirectamente en que sea un producto el que nos permita mejorar nuestra condición y, así, descarga toda nuestra responsabilidad hacia la tecnología, que se espera que funcione como un exo-esqueleto que nos protege. Sin embargo, para Rousseau la tecnología es una armadura que nos dificulta a la hora de hacer ciertos movimientos, pero cuya utilidad valoramos pensando que los beneficios que nos aporta son una ganancia. Tener presente este compromiso es lo que nos plantea la lectura propuesta por Rousseau acerca del uso que hace Platón del mito de Glauco (RAMOS, 2014, p. 153ss.).

Ahora bien, el problema que nos plantea el esquema rousseauista es que la civilización pierde su impunidad y, si queremos hablar de un progreso en lo humano, necesitamos debatir previamente qué consideramos progreso y, sobre todo, replantearnos el sentido y el valor de la tecnología. Por ejemplo, imaginando la situación hipotética en la que un homínido descubre que la dureza de una piedra le permite rasgar o romper la carne o el hueso, no podemos hablar propiamente de un cambio en su condición animal. Desde el esquema rousseauista, este homínido no estaría ante ningún avance hasta que el descubrimiento se le plantee como una moralidad, entendida esta no a partir de la dicotomía bien o mal, sino como una decisión sobre qué es lo que ha descubierto: a) que los objetos que le rodeaban tienen usos ocultos, o bien, b) que puede cambiar lo que le rodea dándole uso.

\section{EL Homo FABER}

Indudablemente, el pensamiento práctico dominante en nuestros días está marcado por una visión conforme a la cual la tecnología se considera parte de nuestra condición. Si preguntamos a cualquiera sobre cómo haría para superar alguna inclemencia -el frío o el calor, por ejemplo-, podemos asegurar que su respuesta implicará algún producto tecnológico-como la 
manta o el abanico- o el uso en términos mecanicistas de nuestro cuerpo -correr para aumentar la temperatura corporal o sumergirnos en agua para disminuirla-. Después de todo, es normal que intentemos solucionar nuestros problemas con aquello que tenemos a mano y no se puede reprochar a nadie el recurrir a soluciones técnicas accesibles. No obstante, cabe reflexionar sobre cómo en vez de plantearnos el problema teóricamente, acudimos a soluciones que, aunque sean complejas en su explicación científica, nos resultan evidentes y accesible en el uso.

Los avances tecnológicos nos permiten transformar nuestro entorno, al mismo tiempo que transforman lo que imaginamos o pensamos: cambian nuestra forma de entender las cosas e introducen nuevas actividades que modifican nuestra manera de vivir. Empero, ¿tales avances nos cambian realmente? La respuesta a esta pregunta podría plantearse en los mismos términos que utilizamos cuando hablamos teóricamente sobre derruir los absolutos que tan amenazantes parecen resultar para el sujeto moderno, ya sea dios, la verdad, el bien, el universo, etc. Si queremos hablar de tales absolutos con cierta propiedad, estamos obligados a aceptar su carácter paradójico y reconocer que, por mucho empeńo que dediquemos a negarlos, los absolutos se presentan al lenguaje de un modo inexpugnable. Cualquier argumento contra ellos es, a fin de cuentas, una manera de honrarlos. Aún más, su presencia en nuestra cultura impregna de tal modo nuestra manera de pensar que sólo parecen ser inútiles cuando los olvidamos o cuando callamos, siguiendo el famoso consejo final del Tractatus. Plantearnos si los quehaceres del ser humano se ven modificados en esencia por la mediación de lo tecnológico nos lleva a pensar en una paradoja similar, para la cual una analogía interesante surge al reflexionar sobre la denominada "realidad virtual", normalmente referida como VR (acrónimo de Virtual Reality). Esta propuesta plasma de manera práctica la posibilidad de una realidad ideal en la que la técnica puede gestionar todas las extensiones a las que el ser humano tiene acceso, de manera que el sujeto conviviría sólo con límites impuestos por la tecnología.

Claudia Giannetti dedica una sección de su libro Estética Digital (2002) a reflexionar sobre las condiciones que debe cumplir un espacio para que podamos considerarlo como una VR. Sus consideraciones tocan relatos, teorías, ejemplos y artefactos que se enfrentan a la posibilidad de generar una realidad distinta a la natural que estaría controlada por el ser humano y que sería capaz de hacernos creer que permanecemos en el ámbito espacial que consideramos natural, aún cuando todas nuestras interacciones estén 
producidas por aparatos tecnológicos. De ahí que, a la hora de poder describir qué condiciones harían posible una simulación así, necesitemos hablar sobre el papel del sujeto observador (el ciudadano de la VR), contar con el aspecto social de la realidad generada (para ser una realidad creíble necesita responder al contexto concreto del individuo observador) y plantear la necesidad de sistemas de retroalimentación lo suficientemente sutiles (si el observador es consciente del sistema tecnológico que genera la realidad replicada, entonces no la confundirá con la original). Giannetti resume estas condiciones en tres implicaciones básicas requeridas por un sistema que intente generar una realidad virtual consistente:

La primera implicación consiste en que, en sistemas interactivos o virtuales, el entorno es dependiente del observador y de su contexto. El sentido de entorno técnicamente construido es asimilado e interpretado por el sujeto a través de la memoria, la percepción, la cognición y la emoción, así como la sensomotricidad y las acciones comunicativas y sensoriales. La segundo, y como consecuencia de ello, que la significación y la efectividad de la obra de Realidad Virtual están estrechamente vinculadas a la actuación del interactor; por consiguiente, la interfaz humano-máquina debe adecuarse al objetivo del sistema respecto a cómo y en qué grado se da la participación del observador. La tercera, que la estructuración abierta y contingente de la obra mina la concepción material, objetual y concluida, característica de la estética ontológica, y transforma el espacio físico en imaginario. (GIANNETTI, 2002, p. 146).

Teniendo en cuenta que la técnica ha sido desde sus inicios una lucha contra las limitaciones físicas para extender nuestra capacidad de acción hasta los límites de nuestra imaginación, acaso sólo cabría considerar que una VR es esencialmente técnica si cumple la tercera implicación que propone Giannetti y logra transformar el espacio físico en imaginario.

Atendiendo a los otros requerimientos que Giannetti propone, encontramos en ellos otras necesidades ontológicas para la formación de una realidad esencialmente técnica. Por un lado, el resultado de tal construcción debe responder en su carácter externo a un diseño y control humano, y por otro lado, en su carácter interno dicho resultado tiene que ser capaz de responder a todos los designios de la imaginación de su habitante. Este planteamiento nos hace preguntarnos: si el sujeto que se mueve por aquella realidad esencialmente tecnológica encontrase limitaciones a su imaginación, ¿no estaría aquella tomando un cariz natural? En otras palabras, ¿no se estaría volviendo agresiva e independiente como aquel reino que lo tecnológico pretende domar? Después 
de todo, se debe tomar en consideración que el diseño de aquella realidad y los medios a través de los cuales el observador de la misma se sumerge en ella serán fruto de una mente humana y una capacidad tecnológica. Como consecuencia, los límites que pudiera encontrar el sujeto deberían ser siempre abarcables y comprensibles, a diferencia de lo que ocurre con los límites que encontramos en el ámbito natural y sus dimensiones macroscópicas y microscópicas, donde, por ejemplo, no existen las propiedades físicas que consideramos normales en nuestra experiencia subjetiva del mundo, como el tiempo o la presión. Aún así, sin embargo, las limitaciones que aportaría el diseño humano tenderían a introducir o borrar afecciones propias de un sistema de referencia basado en el espacio real conocido y una memoria e imaginación personal.

En cierta medida, estas limitaciones deberían resultar comprensibles por cualquier sujeto que comparta un contexto similar, pero esta coincidencia no tiene una razón necesaria para darse. Esto supone que el observador de la realidad necesitaría investigar las resistencias con las que ha sido diseñado el mundo en el que se encuentra antes de poder desarrollar su propia actividad tecnológica en ella. A no ser que, poseyendo un bagaje propio de imágenes, su actividad técnica -en cuanto transformación del medio a través de la imaginación- se desarrollase sin adecuación previa a las resistencias de aquel mundo. ${ }^{3}$ En este último caso, estaríamos efectivamente ante un espacio puramente imaginativo y esencialmente técnico, con lo que el reto sería entonces proveer una tecnología capaz de producir artefactos que todavía no han sido imaginados y que deben responder a la creatividad del usuario. Es decir, el sistema tendría que interactuar con las imaginaciones del observador sin poder recurrir a una referencia ajena. Toda nueva creación sería una creación de la imaginación del individuo, por lo que aquello que la técnica estaría aportando sería un espacio en el cual plasmar los nuevos artefactos, esto es, un papel en blanco y no una realidad. Sujeto y sistema estarían produciendo así un reino que iría más allá de lo imaginable, sin puntos de partida, y se tendría que hablar no ya de imaginación sino de fantasía.

Aún más, cabe seńalar la posibilidad de que, en el caso que nos ocupa, el observador fuese un recién nacido y, por tanto, sólo pudiese generar imágenes

\footnotetext{
${ }^{3} \mathrm{Al}$ respecto, resulta interesante la siguiente reflexión de Gilbert Simondon en Du mode d'existence des objets techniques: "[E]s permisible pensar que el dualismo inherente al pensamiento filosófico, un dualismo de principios y actitudes debido a la doble referencia a lo teórico y lo práctico, será profundamente modificado por la introducción de la actividad técnica considerada como un área de reflexión en el pensamiento filosófico." (SIMONDON, 1989, p. 256). Agradecemos a uno de los revisores por su referencia a ese trabajo.
} 
a partir de lo que le ofrece el sistema, no pudiendo por ende generar imagen alguna. Sería de esperar que esta VR sólo tuviese que funcionar de un modo similar a una placenta que reacciona ante las necesidades fisiológicas del feto, siendo capaz de identificar gestos carentes de sentido. Ante ello, lo único que a nuestro parecer se puede concluir con certeza es que la posibilidad de una VR esencialmente técnica se pierde en un entramado de suposiciones teóricas y juegos de posibles situaciones de las que el ser humano no hace más que escaparse o dificultar su posibilidad.

En la obra de ficción 2001: Una odisea del espacio, tanto en la narración de Kubrick como la de Clarke se plantea la posibilidad de una VR generada a través de lo que una especie alienígena logra aprender sobre el ser humano mediante las imágenes de la televisión y análisis fisiológicos. La imaginación de Clarke y Kubrick nos describen un espacio que intenta resultar reconocible para el observador pero que le resulta más particular de lo que desearían sus diseñadores. El primer fallo que descubre el observador es de carácter histórico. Los alienígenas reproducen la habitación de un hotel que para el observador está ubicada en un tiempo pasado que no se corresponde con el suyo. Esto se explica por qué el observador accede a las imágenes que constituyen el cuarto desde un contexto que no las vincula con un tiempo concreto. Lo que para los alienígenas son imágenes relativas a un lugar que podría ocupar un ser humano de manera ahistórica, para el observador son imágenes relativas a un espacio y un contexto histórico particular. Aunado a lo cual, otro aspecto que diluye la realidad de la habitación de hotel es que las cosas dispuestas en la habitación se agotan en su apariencia. Por ejemplo, el lomo de cada libro de una estantería anuncia una historia, pero sus páginas están en blanco. Son productos que funcionan como libro para la estantería, pero no funcionan como libro para el observador, que reconoce sus carencias sin necesidad de conocer el contenido del libro. Los alienígenas, en este caso, no habrían sabido manejar las expectativas que las cosas producen en los sujetos. Por último, la curiosidad más llamativa de esta ficción literaria es la sustitución del agua y los alimentos por un gel azul que aporta todos los nutrientes que necesita el observador siguiendo un preciso análisis fisiológico del animal ser humano: se trata de una solución tecnológica excelente, pero que produce una terrible insatisfacción al observador. La ficción de Clarke y Kubrick recoge, por ende, la idea que normalmente manejamos de lo que sería una VR con sus paradojas.

Ahora bien, entendemos que VR es una reconstrucción aquí de lo que no está, una especie de visita guiada a un lugar distinto del que nos 
encontramos. Así, su interés no sería tanto la generación de un espacio técnico sino la reproducción tecnológica de un espacio que consideramos real. La definición terminológica que Giannetti hace de VR responde al objetivo de que la virtualidad tenga sentido en tanto que nos ofrece una manera distinta de hacer lo mismo:

Realidad Virtual (RV): Realidad generada por ordenador. El sistema puede sumergir (proceso de inmersión) al usuario en la ilusión de un mundo generado por ordenador y permitirle recorrer este mundo a voluntad. Para ello, el usuario utiliza interfaces como el casco de datos (Head Mounted Display), que despliegan imágenes estereoscópicas, o los guantes de datos (Data Glove) o traje de datos (Data Suit), que le permiten manejar objetos virtuales o desplazarse en el ambiente virtual. El rango de aplicaciones potenciales incluye la arquitectura, la medicina, el arte, el entretenimiento, etc. [...] Desde la perspectiva ontológica, lo virtual significa lo que proviene de lo posible y se aproxima a la realidad. (GIANNETTI, 2002, p. 196).

Parece suceder con la VR lo mismo que con muchos tipos de estupefacientes que sólo sirven como medio para alcanzar un objetivo difuso y es imposible que tengan sentido como sistema cerrado. Podemos compararla con los alucinógenos y estimulantes que nos ofrecen nuevas sensaciones o una distorsión sensorial, carentes de valor para el individuo per se, pero atractivas porque cambian nuestra manera de percibir las cosas. Enfrente, surgiría inmutable la única droga que parece ser fin en sí misma, la única que funciona como soma, la heroína, que nos aporta una felicidad autónoma a cambio de consumirnos, de esclavizar nuestro cuerpo como medio y convertirse, ella, en fin. La VR, no lograría, ni siquiera teóricamente, suplir todos los aspectos de la realidad física porque parece haber en el ser humano un deseo de enemigos, de resistencias que superar. Nuestros anhelos no son un folio blanco, sino una historia que contar, y preferimos resolver los problemas a que la solución surja de nuestra fantasía. Lo que buscamos, y la manera en la que pensamos en una VR, se podría entender como el capricho de vivir lo mismo, pero por causas distintas y con la capacidad de modificar levemente nuestra experiencia mezclando diferentes elementos de nuestra imaginación ${ }^{4}$.

Un recién nacido podría encontrar en una VR capaz de entender y responder a todas sus necesidades el fin para su existencia, pero esta posibilidad

\footnotetext{
${ }^{4}$ Esta visión de la VR se deriva del hecho que implica una reubicación de la consciencia. Esta condición se articula en la primera conferencia del ciclo Consciousness Reframed (cf. JONES, 2000) y ha servido para desarrollar una reflexión continuada que ya supera las 20 ediciones.
} 
supone hablar de un individuo que nunca abandonaría un estado fetal; idea explotada por la franquicia cinematográfica Matrix. Un adulto nunca podría encontrar una respuesta equivalente porque necesitaría importar imágenes externas al sistema y con ellas heredaría una determinada experiencia de un orden natural, por lo cual su existencia no se desarrollaría nunca en un espacio generado por la técnica sino en uno reproducido. En el estado fetal virtual, el individuo podría creer que la noche no existe, mientras que en una VR tendríamos que convencer al observador de que ha llegado a un espacio iluminado por el sol de medianoche polar o utilizar alguna argucia similar. En este sentido, todas nuestras elucubraciones sobre la VR descubren las deficiencias del planteamiento que hemos presentado. Si partimos de que la tecnología es la forma en la que el ser humano impone a la realidad aquello que logra imaginar para transformar su entorno en un lugar acorde a sus necesidades, ¡cómo podemos sopesar la posibilidad de que el ser humano se origina con la actividad técnica cuando señalamos la existencia de productos humanos previos?

En un pasaje del manifiesto "Profesión de fe", que Jean-Jacques Rousseau introduce en Emilio, se plantea la cuestión del instinto animal y de cómo, a pesar de lo que se suele decir, no tenemos por qué haberlo perdido, puesto que, simplemente, siempre hemos carecido de él. El argumento que Rousseau utiliza es que los animales, al actuar a través del instinto, realizan su actividad de una manera que podemos considerar ciega; es decir, los animales no toman en cuenta nada de lo que observan porque las sensaciones que perciben se convierten directamente en una reacción. Así, los sentidos del animal funcionan como resorte mientras que en el ser humano los sentidos actúan como filtro porque éste muestra una actitud pasiva ante las sensaciones. Frente a los reflejos y conductas automatizadas del animal, nosotros tomamos decisiones sobre las percepciones. Utilizamos los sentidos como fuente de información, pero recibimos solo datos en crudo que nuestra consciencia tiene que ordenar para que tengan algún sentido. Ante las sensaciones desordenadas que recibimos, tenemos que decidir, siendo esta una acción fundadora de lo humano, un acto de carácter moral, posibilitado por una voluntad autónoma: "La duda sobre las cosas que nos importa conocer es un estado violento para el espíritu humano; no la resiste durante mucho tiempo, se decide, a su pesar, de una manera u otra, y prefiere equivocarse antes que no creer en nada" (ROUSSEAU, 1999, p. 568). El planteamiento parte de la existencia individual como algo evidente y se articula sobre el origen de lo humano en la duda generada por un mundo exterior que no se amolda a nuestra voluntad. 
La secuencia comienza con la necesidad de confiar en las imágenes del mundo exterior a través de un juicio como la primera actividad humana, tras lo cual esas imágenes se usarán para ordenar un mundo de interacciones que adquieren mayor complejidad con el uso que hace del mismo y ante el cual su instinto es más y más insignificante e inútil. Es un planteamiento que acude a la actividad para explicar el origen del ser humano, sólo que, descomponiendo los elementos que se manejan para producir cada gesto dentro de la segunda naturaleza, encuentra que no hay una necesidad de productos humanos anteriores. El homo faber, el ser humano constructor no lo es sólo en cuanto al uso de herramientas, sino que la adecuación de lo externo a su fisiología comienza con la construcción de un mundo externo.

Afirmar que el ser humano surge de la técnica es un postulado que sólo sería posible si le otorgáramos a la tecnología el poder de generar un mundo externo además de ser una fuerza transformadora. Aún más, tal postulado sólo es posible si, siguiendo a Gilbert Simondon, se afirma que "hay algo de naturaleza humana en el ser técnico, [...] el remanente de lo original, previo incluso a la humanidad constituida en el ser humano." (SIMONDON, 1989, p. 248). Por el contrario, en nuestro contexto cultural, lo intuitivo es afirmar que el reino tecnológico surge a partir del conocimiento científico, que el pensamiento es previo a la acción técnica. Asumimos que analizar lo real de una manera racional para establecer reacciones previsibles e imaginando los entresijos que relacionan unos eventos con otros, es algo previo a la construcción de artefactos capaces de reproducir, modificar o desviar el sentido natural del mundo respecto a lo que nosotros mismos hemos aprendido a predecir. Pero esta visión pasa por considerar que la tecnología no es un producto cultural, argumento que resulta complicado de defender sin caer en una escrupulosidad conceptual exagerada a la hora de definir "artefacto", o por afirmar que la tecnología es un subproducto cultural de la ciencia, cuando la tecnología, como ya se ha comentado, es algo que conocemos por su uso y que no requiere de conocimientos científicos para ser usable, para modificar la función de un artefacto ni para crearlo: el botijo ha enfriado agua mucho antes de que poseyésemos los conocimientos necesarios para explicar el complejo proceso termofísico por el que funciona. El caso de la VR, por lo tanto, nos obliga a pensar de otra forma, a hablar de un halo tecnológico que intenta sustituir la interacción del sujeto con el espacio natural por una relación controlada desde la voluntad del observador, y nos obliga a no perder de vista que el sujeto que está inmerso en esa VR no podrá ser engañado fácilmente respecto las interacciones con el mundo que él mismo ha desarrollado, pues los usos que 
le damos a la tecnología son personales y hay quien no necesita que los libros digan algo más que lo que pone en su lomo.

\section{LA TECNOLOGÍA COMO PARTE DE LO HUMANO}

Al establecer los objetivos de su trabajo Técnica y sociedad (1998), Lewis Mumford plantea la necesidad de conocer la cara humana de la máquina. Una cara que no debe ser interpretada como aquella que nos sirve para ver con esperanza los artefactos, ni aquella guía de diseño para crear objetos cálidos para el usuario o aquel discurso con el que exculpar éticamente al artefacto. La cara humana de la máquina, en cambio, es el reflejo de nuestros deseos, pensamientos, inquietudes y capacidades.

El estudio de Mumford chocó en su momento con una corriente de pensamiento establecida que entendía que la máquina era un hijo ya independizado del ser humano y tenía su propio devenir. Mumford, por su parte, quiere evitar una escisión que le parece inadecuada. Si tenemos en cuenta, primero, que la misma máquina recibe distintos usos en distintas comunidades, $y$, segundo, que comunidades que tienen acceso a las mismas máquinas evolucionan de forma distinta, ¿podemos afirmar que la máquina se ha independizado o sucede todo lo contrario? Lo que sucede en las distintas comunidades humanas nos dice que el ser humano y la máquina conviven en un lugar común. Con la máquina sucede lo mismo que con las distintas religiones, literaturas, lenguas y políticas: todas tienen una historia propia pero afincada en un marco social concreto. La máquina es un producto más del homo faber, la producimos nosotros, los seres humanos, por lo que comparte nuestros límites, nuestro mundo y, como producto, está sometida a nuestros designios. En resumen, la máquina está muy lejos de ser algo ajeno o independiente de lo humano.

Cuando tratamos cuestiones relativas al espacio y al tiempo, solemos hablar a un demiurgo que ordena o desordena según su propia voluntad o idea, de manera que descargamos nuestras responsabilidades y miedos en una voluntad superior. Sin embargo, en lo relativo a las cosas que han surgido de nuestra imaginación, tenemos la obligación de reconocerlas siempre como propias. La ética, la ontología y la estética de los artefactos nos lo recuerda y aunque reneguemos de aquello que ha sido construido por un ser humano, el artefacto nos seguirá perteneciendo. Esquivar nuestras responsabilidades sobre lo tecnológico, o dudar de ellas, sólo nos ayuda a alejarnos de aquello de lo que 
somos responsables y con lo que convivimos. El olvido puede servirnos como una cura momentánea, pero seguiremos siendo los únicos responsables de nuestras imaginaciones y su actividad siempre repercutirá en nosotros tarde o temprano. Podemos cerrar los ojos e intentar soñar un universo automatizado en el que la máquina no nos pide cuentas, pero su ordenación en el mundo de las cosas es fruto de nuestros gestos y por tanto tan humana como el propio ser humano.

Una de las formas a través de las cuales intentamos liberarnos de la responsabilidad que tenemos sobre la tecnología es predicar que la tecnología tiene su propio devenir. A este respecto, es cierto que podemos escribir una historia de los artefactos desde una lógica interna, recorriendo sus evoluciones como un destino propio, pero la causa eficiente de todas sus transformaciones no es una fuerza espontánea. Tal vez no hubiésemos conocido las impresoras de inyección de tinta si no hubiésemos usado antes la imprenta y la pluma estilográfica, pero la secuencia temporal de la implantación de cada una de estas tecnologías en nuestra sociedad occidental no parece atender a ninguna lógica propia del artefacto mismo sino a cuestiones de avances dispares en la tecnología necesaria por los distintos componentes de cada aparato. De ahí que podamos concebir comunidades ideales en las que, si bien no se ha conocido la imprenta, sí se usen impresoras de inyección de tinta y plumas estilográficas o comunidades donde sólo se usen imprentas y plumas estilográficas aún si poseen la tecnología necesaria para fabricar impresoras. Precisamente, en el desarrollo de la primera computadora digital encontramos una situación similar. En el siglo XIX, Charles Babbage diseñó su máquina analítica como artefacto mecánico que no pudo construir porque en su época no se podían fabricar ruedas, engranajes y levas lo suficientemente precisas. En cambio, hoy podríamos construir engranajes y levas lo suficientemente precisas muy rápidamente gracias a la reconstrucción de aquel modelo mecánico en un modelo basado en componentes electrónicos. Como consecuencia, no tenemos interés en construir aquella máquina analítica porque consideramos que la computadora digital es una alternativa mejor, pese a lo cual cabe preguntarse qué habría hecho Babbage en esta situación: ¿seguiría interesado en construir una computadora mecánica? ¿Habría hecho su diseño directamente sobre componentes electrónicos si tuviese conocimiento de ellos? Las respuestas a estas preguntas sólo podría darlas un sujeto que reconstruimos a través de supuestos sin fundamento. 
Una historia teórica que intente describir el desarrollo de una tecnología concreta atendiendo a una lógica práctica o interna de la misma tenderá siempre a corresponderse con una secuencia caótica de avances y regresiones en la historia de la humanidad. Incluso, podríamos afirmar que si la historia de los artefactos estuviese realmente marcada por una causalidad tecnológica, la historia de los seres humanos jamás habría generado la cantidad de basura que aún produce. Es por ello que debemos hacernos eco de los objetivos propuestos por Mumford, quien considera que resulta inevitable estudiar el uso que recibe y las intenciones que acompañan la creación de cada aparato si queremos conocerlo. Tenemos que esforzarnos en conocer verdaderamente el artefacto y su contexto porque ser humano y artefacto conviven en un mismo lugar y la influencia que tiene el segundo en el primero es la misma que cualquier otro producto humano. Conocer un artefacto supone conocer también la cultura en la que se crea, al ser humano que normaliza su uso y la modificación en el contexto que lo acepta. Dicho de otra manera, conocer el artefacto nos permite también conocernos a nosotros mismos un poco más: "La máquina misma no tiene exigencias ni fines: es el espíritu humano el que tiene exigencias y establece las finalidades." (MUMFORD, 1998, p. 24).

En la actualidad, el planteamiento de Mumford encuentra un entorno más amigable. Las disciplinas denominadas humanistas han desarrollado ramas dedicadas al estudio de lo tecnológico y las disciplinas denominadas científicas entienden su historia como parte de un contexto general mayor. Hoy es común hablar sobre la máquina y otros productos tecnológicos tomando siempre en consideración contextos ideológicos, sociales, técnicos y materiales. Se intenta entender la cultura que da forma y se retroalimenta de cada artefacto. Pero esta nueva situación dista mucho de ser ideal. El propio Mumford nos advierte que "nuestra capacidad para ir más allá de la máquina depende de nuestro poder para asimilarla. Hasta que no hayamos aprendido las lecciones de nuestro reino mecánico, no podemos ir más allá en nuestro desarrollo hacia lo más ricamente orgánico, lo más profundamente humano." (MUMFORD, 1998, p. 384). Hoy, en cambio, la atención que se le presta a la máquina tiene más de fascinación que de asimilación, reina un espíritu que se agota en la máquina y olvida que, detrás del artefacto, debe estar lo profundamente humano. La tendencia mayoritaria no parece ver en la técnica un medio sino un nuevo fin y es normal que surjan, entremedias, posiciones que incluso reniegan de lo humano. Es cierto que los extremismos no deben ser considerados como una vía que pueda volverse mayoritaria, no hay que tenerles miedo, pero sí debemos tenerlos en cuenta como síntoma de los posibles malestares y desequilibrios 
latentes. La presencia de la tecnología como parte de la cuestión no significa que esta haya sido considerada como le corresponde. Es necesario llevar el artefacto hasta lo más profundamente humano que menciona Mumford, una posición sensata, alejada de una actividad pasional y fanática, que atiende a los hechos y las razones de un modo sosegado intentando encontrar la solución más eficiente. La convivencia con la tecnología debería servir para resolver problemas sin introducir, a cada paso, nuevas dificultades. Su presencia en nuestro mundo no debe suponer un dilema entre técnica y naturaleza, o ser humano y máquina, porque todos ellos tienen cabida:

\begin{abstract}
Al discutir las técnicas modernas, hemos avanzado tan lejos como nos parece posible considerando la civilización mecánica como un sistema aislado: el próximo paso para orientar nuevamente nuestra técnica consiste en ponerla más complemente en armonía con los nuevos patrones culturales, regionales, societarios y personales que hemos empezado a desarrollar coordinadamente. Sería un gran error buscar enteramente dentro del terreno de la técnica una respuesta a todos los problemas que la misma ha suscitado. Pues el instrumento sólo en parte determina el carácter de la sinfonía o reacción del auditorio: el compositor, los músicos y el auditorio también han de ser tenidos en cuenta. (MUMFORD, 1998, p. 457).
\end{abstract}

\title{
3 TeCnología y Fascinación
}

Desgraciadamente, los discursos sobre la técnica que suelen adquirir mayor publicidad son los que alimentan el miedo y el desconocimiento de los lectores. Son discursos y propuestas marcadas por la fascinación y la escisión, en los cuales los argumentos, que parecen leyendas propias de una novela de ciencia-ficción, promueven la visión de que la tecnología es algo especial que va incluso más allá de nuestra realidad. Visiones en las que la VR se presenta como un espacio trascendente o en las que la tecnología adquiere un factor disruptivo que va a quebrar nuestra experiencia actual con el mundo, como si el desarrollo de nuevas tecnologías no lo hubiese hecho ya desde los primeros sílex. Un ejemplo de este tipo de mezclas sería la descripción que Giannetti (2002, p. 197) realiza del concepto "tiempo real":

Denominación para el tiempo de reacción muy breve del ordenador, condicionado a una gran capacidad y velocidad de procesamiento de datos, que es inferior a la capacidad de percepción humana del desfaz, es decir, da la sensación de inmediatez entre acción y reacción. El computador es generalmente capaz de presentar los resultados con la suficiente rapidez como para controlar y permitir hacer cambios en el proceso. Como valoran algunos científicos, el tiempo real efectivo todavía es una ilusión. 
Desde un punto de vista informático, que tendría que ser el aplicable si se menciona la intervención de computadoras, esta definición tiene poco sentido. El tiempo real computacional no tiene nada que ver con el tiempo de reacción de un equipo informático, la percepción humana del desfaz o con la capacidad y velocidad de procesamiento de datos. De hecho, la incapacidad humana de percibir la distancia entre acción y reacción es la vivencia más común que ha tenido cualquier usuario de ordenadores personales y otros sistemas electrónicos desde principios de la década de los años 80 al presionar una tecla.

Es cierto que los primeros usuarios de computadoras, aquellos que tenían que esperar a que se produjese un proceso mecánico basado en tubos de vacío, tenían que esperar un desfaz de horas que, en cambio, para el sistema, no era más que una tarea. Pero en aquellos tiempos, las computadoras no se ocupaban de cómo se introducían datos ni de cómo se exponían los resultados: los usuarios eran, en realidad, operarios y la informática era solo una automatización del cálculo. Desde que el operario se ha convertido en usuario y los sistemas informáticos gestionan también la información de las operaciones, el desfaz de respuesta del sistema ha sido prácticamente imperceptible. Todos los que hemos tocado una tecla y hemos visto aparecer una letra en un monitor o hemos movido el joystick y hemos visto reaccionar un polígono, podemos confirmarlo. Tanto es así, que muchos serán los que identifiquen las interacciones con el interfaz con un proceso mecánico, pero la transmisión de datos a través de los cables o una conexión Bluetooth implica un proceso computacional.

El desfaz que menciona Giannetti solo puede entenderse en relación con la impaciencia con la que el usuario espera el resultado de un proceso complejo. En este sentido, sí que cabría hablar de un desfaz, pero no como un problema en cuanto a su percepción sino en cuanto a la imposición de un tiempo limitado por parte del usuario, contexto en el que sí estaríamos hablando con propiedad del "tiempo real" en sentido informático, entendido éste como el ajuste del ordenador a la petición del usuario. No obstante, no por esto se puede confundir el tiempo real con la computación de altas prestaciones. La velocidad de los procesadores en el ańo 2002, que es cuando Giannetti escribe su definición, ya permitía realizar simulaciones físicas sencillas a mayor velocidad de lo que el ser humano puede percibir. Así, la computación de altas prestaciones permite mejorar el tiempo real en 
cuanto problema de percepción, aunque esta cuestión no tiene que ver con computación en tiempo real para las ciencias computacionales.

Un ejemplo clásico del problema de computación en tiempo real es una partida de ajedrez con un tiempo limitado para cada jugada. Para la computadora el tiempo son ciclos, entendidos como la realización de una serie de operaciones para obtener un resultado, y escoge tras completar la tarea de simular las jugadas posibles según el estado del tablero. Al introducir una limitación temporal, la decisión tendrá que tomarse según el estado en el que se encuentran sus operaciones en un momento concreto, antes de completar la tarea. Con este condicionamiento externo, para evitar su movimiento sea fruto del azar, debe programarse una solución que prediga esta eventualidad, como, por ejemplo, que el mejor movimiento hasta el momento prevalezca como respuesta. Aumentar la velocidad del procesador para que la computadora pueda completar la tarea en el tiempo que se le proporciona puede ser una solución práctica, pero no perdamos de vista que el problema teórico prevalece.

Por tanto, el planteamiento de Giannetti sobre el tiempo real está desubicado, dado que lo importante no es la impresión ni la percepción del usuario, sino un problema de adecuación entre un sistema analítico y la experiencia de continuidad en el mundo real. Giannetti parece caer en una cierta fascinación por los conceptos, dándoles un carácter expositivo de una cuestión práctica general más allá del problema teórico que refieren y que es el que se concreta en escenarios prácticos particulares. Las ciencias computacionales tienen una dimensión teórica que se expresa en su uso de la matemática o en el diseño de sistemas intercambiables, como los protocolos de red, pero siempre en diálogo con problemas y soluciones que tienen un carácter práctico que, en sus diferentes casos, nos permiten entender mejor el reto al que nos enfrentamos. Una situación muy acorde con la propuesta de Mumford, en la medida en que, para entender lo que sucede en el ámbito tecnológico, debemos adoptar una razón funcional tan mecánica como ordenar engranajes o soldar condensadores, evitando las boutades en las que la máquina parece existir para dar rienda suelta a nuestra fantasía.

Es cierto que hoy hemos disminuido la escisión que se había dado desde los inicios de la Modernidad entre el ser humano y la tecnología (MUMFORD, 1998, Capítulos 2 y 3), que ya no demonizamos los logros técnicos por regla general y que el ingeniero ya no es un alquimista, pero parece inevitable que la tecnología siga fascinándonos. Nos cuesta aceptar que la magia no reside el filamento incandescente que ilumina desde una burbuja 
de cristal, sino en poder utilizar todas las noches una bombilla para iluminar nuestras casas; algo que nunca podría llevar a cabo un solo individuo. Todos los artefactos que nos sorprenden requieren el sustento de un entramado social que lo hace posible y que nos fascina, en tanto que lo que nos ofrece ese artefacto es la transformación de nuestras interacciones con la realidad a través de la perspectiva de otro. Parece que nos negamos a aceptar que las cosas tecnológicas expresan una sociedad compleja y preferimos tratarlos como una posesión completamente individual una vez que nos apropiamos de su uso. ¿No vemos lo disparatado que resulta considerar como posesión privada un equipo dependiente de una red eléctrica o de una red de abastecimiento de carburantes? Convivimos con la tecnología sin entender que todos los artefactos tienden a la transparencia.

\section{CONCLUSIONES: LA TRANSPARENCIA}

Cuando nos entregamos a la fascinación que nos producen los relatos de otros, delegamos nuestra comprensión del mundo en otro, en un intermediario. Podemos convertimos en víctimas del alcahuete que reina en el "teatro de la envida" descrito por René Girard -autor que, desde su cátedra en Stanford ha fascinado a Silicon Valley (GIRARD, 2014, capítulo IX). Los estudios científicos requieren de un entramado social ordenado que evite caer en la perplejidad de un solo científico. Se obliga a que todos los estudios puedan ser verificados y esculcados por el mayor número de ojos en busca de una posición lo más objetiva posible. Es por ese motivo por lo que consideramos que los resultados que se publican dentro de un contexto científico son valiosos, en términos de conocimiento, y no solo una boutade de su autor. Sin aplicar el mismo rigor y exigir que la tecnología pueda ser explicada correctamente por quien la presenta, estamos abocados a escuchar y perdernos entre cantos de sirena. Parece propio del ser humano reaccionar ante la novedad buscando una explicación esotérica que le permita despreocuparse. Una actividad que, en el ámbito de lo tecnológico, se simplifica porque uno de los objetivos que el propio desarrollo tecnológico persigue es que el usuario no tenga que hacerse cargo de las incomodidades y que la experiencia de lo tecnológico se mimetice con su identidad: que interactuemos con un amigo, que confiemos en que nuestras experiencias no están siendo intervenidas y en que nuestras emociones no se deben a la fuerza mimética que discute Girard. 
Así, cuando hablamos de la VR (que no es más que una manera de utilizar unos recursos computacionales), enseguida afloran prejuicios sobre la virtualidad del proceso y de que si el mundo al que vamos a viajar está producido por una máquina fuera de nuestro control. Como ya hemos seńalado, este no es el caso pues aún en los escenarios producidos a partir de objetos fractales que la computadora combina aleatoriamente, todo lo que sucede dentro del simulador está programado por humanos, por mucho que sea producido por máquinas. La singularidad y la posibilidad de que aparezca una inteligencia artificial a la altura de las que programan los guionistas de las películas más oscuras sobre este tema todavía está lejos y necesitamos mejorar nuestros modelos matemáticos para que sea realmente posible. Las redes neuronales han conseguido aprender incluso conceptos subjetivos para crear obras artísticas (FANG; ZHANG, 2017), pero los conceptos subjetivos que imitan siguen siendo producidos al gusto del ser humano que las adiestra y adecuados a una interacción social entre millones de humanos. Lo que hace que, en el caso de la singularidad, nos encontremos con la misma paradoja que en el de la VR: el pensamiento artificial estaría limitado por el pensamiento del ser humano y solo lo reconoceríamos como singularidad desde una perspectiva humana. La singularidad, por ende, no podría por ello ser realmente un pensamiento artificial sin la presencia previa de una civilización artificial, o, mejor dicho, de computadoras. El mismo panorama que dibuja Rousseau con la idea de la segunda naturaleza.

Una manera de ilustrar de manera práctica esta situación es pensar la posibilidad de que una máquina decidiese acabar con la humanidad. Nuestra imaginación genera al respecto situaciones bélicas propias de novelas y películas de ciencia-ficción. En cambio, ¿qué interés puede tener una computadora en guerrear? Los humanos golpeamos a otro individuo acuciados por un objetivo que nos urge e intentando violentar su voluntad, pero ¿qué nos hace pensar que una computadora actuaría de este modo? Como comentábamos, el tiempo para una computadora es completar una tarea, alcanzar un resultado. Para una computadora, acabar con la humanidad no tiene urgencia y seguramente tome decisiones con un carácter más técnico, como la eficacia. En este sentido, la violencia puede ser efectiva, pero no necesariamente eficaz. Sin mucho esfuerzo, podemos imaginar alternativas como destruir nuestros vínculos sociales hasta que la humanidad se desintegre en individuos incapaces de hacer perdurar la especie. Un futuro que muchos auguran ya afirmando que pasamos demasiado tiempo con los teléfonos móviles; este plan podría estar ya en marcha y completarse sin que opusiésemos la mínima resistencia otorgándole a la 
máquina una victoria muy eficaz. Pero no, seguiremos imaginando una guerra entre ser humano y máquina y, seguramente, acertemos porque, de momento, somos nosotros los que programamos las computadoras y "sin su software, la computadora es básicamente un montón de metal inútil. Con su software, una computadora puede almacenar, procesar y recuperar información; exhibir documentos multimedia; realizar búsquedas en internet y realizar muchas otras actividades valiosas para justificar su existencia" (TANENBAUM; WOODHULL, 1998, p. 1); ¿no podría ser el atemorizarnos con una guerra una actividad que las hacen valiosas?

Durante la WWDC 2017, Apple ha introducido un framework para el desarrollo de aplicaciones de Realidad Aumentada, ARKit (Augmented Reality Kit), que confirma que la industria tecnológica ha abandonado la realidad virtual en favor de la realidad aumentada. Este nuevo paradigma ha ido creciendo poco a poco con la expectación que ha generado la start-up Magic Leap o la aceptación por parte del público de los filtros que introdujo la aplicación Snapchat y que Facebook ha ańadido últimamente a las diferentes redes sociales que gestiona; si bien, pocos saben identificar como una aplicación de la realidad aumentada esta tecnología. Las empresas apuestan por la AR frente a la VR por la transparencia con la que llega al usuario, que solo ve un nueva feature en un artefacto que utiliza a diario. La posibilidad de identificar un árbol solo con enfocarlo con la cámara de nuestro móvil, un gesto que ya se popularizó en la ciencia ficción de los años 80 con películas como Terminator (1984) o Robocop (1987), no es algo disruptivo. En cambio, la VR, que películas como The Lawnmower Man (1992) presenta como una experiencia de carácter místico capaz de desnaturalizarnos, sí lo son. A la VR le ha faltado transparencia desde su concepción y esto la ha delegado a nichos como el entretenimiento o la educación, mientras que la AR se consolida sin que seamos conscientes de ello como una tecnología de consumo popular y cotidiano que no nos fascina aunque nuestra interacción con las cosas y el funcionamiento de nuestra sociedad cambie completamente. Dependeremos cada vez más de la $\mathrm{AR}$, como ocurre, por ejemplo, en las zonas urbanas de China, donde los pagos se realizan a través de códigos QR. La AR pasará a ser una de esas tecnologías que, como el lenguaje, nadie recuerda que lo son y por eso nadie pone en duda hasta que se ponen de moda palabras como post-verdad y volvemos a pensar en cómo usamos el lenguaje. Es decir, hasta que surgen problemas concretos que intentamos solucionar con más o menos tecnología para seguir progresando, pues, como señalaba Mumford, la historia 
de la tecnología es la historia del qué y cómo se transforma nuestro mundo, no de lo que etiquetamos como tecnología.

RAMOS, I.; GUILLÉN, E. F. Technology and Transparency. Trans/form/ação, Marília, v. 43, n. 1, p. 77-98, Jan./Mar., 2020.

\begin{abstract}
The idea of the human being as a technological animal, coupled with the idea of progress as the very foundation of civilization, raises several issues that need to be carefully considered, including the meaning of progress and the meaning and value of technology. The case of virtual reality (VR) indeed makes explicit the common assumption of technology as something alien to cultural, human production. However, technology shares our limits and it is subject to our plans, regardless of whether someone insists on assuming it independent of ourselves or insists on replacing our interaction with natural space by an interaction in an entirely controlled virtual environment.
\end{abstract}

KeYwORDS: Society. Technology. Transparency. User.

\title{
REFERÊNCIAS
}

FANG, Hui; ZHANG, Meng. Creatism: A deep-learning photographer capable of creating professional work. arXiv, Nova York, 2017. Disponivel em: https://arxiv.org/ pdf/1707.03491v1.pdf. Acesso em 20 de jan. 2019

GIANNETTI, Claudia. Estética digital. Sintopía del arte, la ciencia y la tecnología. Barcelona: ACC L’Angelot, 2002.

GIRARD, René. Shakespeare, les feux de l'envie. Paris: Grasset, 2014.

JONES, Stephen. Towards a Philosophy of Virtual Reality: Issues Implicit in "Consciousness Reframed". Leonardo, Cambridge, v. 33, n. 2, p. 125-132, abr. 2000. doi:10.1162/002409400552388.

MORGAN, Lewis Henry. La sociedad primitiva. Madrid: Ayuso, 1975.

MUMFORD, Lewis. Técnica y Civilización. Madrid: Alianza, 1998.

RAMOS, Iago. Rousseau y el ser del hombre. Salamanca: Ediciones de la Universidad de Salamanca, 2014.

ROUSSEAU, Jean-Jacques. Essai sur l'origine des langues. In: ROUSSEAU, Jean-Jacques. CEuvres Complètes. Paris: Éditions Gallimard, Bibliothèque de la Pléiade, 1995. t. V. 
ROUSSEAU, Jean-Jacques. Émile, ou de l'éducation. In: ROUSSEAU, Jean-Jacques. Euvres Complètes. Paris: Éditions Gallimard, Bibliothèque de la Pléiade, 1999. t. IV.

SIMONDON, Gilbert. Du mode d'existence des objets techniques. France: Aubier, 1989.

TANENBAUM, Andrew; WOODHULL, Albert. Sistemas operativos. Diseño e implementación. 2. ed. Naucalpan: Prentice Hall Hispanoamericana, 1998.

TOMASELLO, Michael. Why we cooperate. Londres: The MIT Press, 2009. 


\title{
Comentário
}

\section{Tecnología y Transparencia}

\author{
Evandro Smarieri Soares ${ }^{6}$
}

Tecnología y transparencia traz uma reflexão que conecta dois extremos: a gênese do ser humano enquanto ser social e a possibilidade da superaçáo das capacidades humanas pelas máquinas. As conclusóes que os autores alcançam, corroborando o trabalho de Lewis Mumford, apontam para uma leitura antropocentrada que, para se oporem à fascinação pelas máquinas, acaba, a meu ver, subestimando o papel dos objetos técnicos.

É certo que a tecnologia é um produto cultural dos humanos e que está atrelada às limitaçóes destes. Logo, a ideia de uma superação das capacidades humanas pelas máquinas é fruto de uma compreensão parcial do modo de existência desses seres técnicos. Como pretendo mostrar, pressupor que a tecnologia é parte integrante da cultura náo nos impede de considerar a hipótese do devir próprio das técnicas. De outro lado, negá-lo pode impedir de compreender de maneira justa a importância da tecnologia para um entendimento filosófico da realidade.

Pretendo introduzir a hipótese do devir técnico ao debate, a partir do conceito de objeto técnico, como encontrado em Du mode d'existence des objets techniques (SIMONDON, 1989). Ademais, ao nos debruçarmos sobre esse conceito, estamos corroborando a proposta de conhecer a "cara humana das máquinas" que, enquanto objetos técnicos, são portadoras de humanidade em sua essência, mas não se restringem a um simples "[...] reflexo de nossos desejos, pensamentos, inquietudes e capacidades", como afirmam Ramos e Fuentes, neste texto.

\footnotetext{
${ }^{6}$ Doutorando em Sociologia pela Universidade Estadual de Campinas - UNICAMP. orcid.org/0000-0002-8699-4813. Email: esmasoares@gmail.com.

http://dx.doi.org/10.1590/0101-3173.2019.v43n1.06.p99
}

https:// 
A negação do devir técnico implica uma abordagem das máquinas que é conflitante com a de Simondon, porque privilegia o desígnio humano sobre os seres técnicos, incorrendo no que o autor descreve como hilemorfismo (SIMONDON, 1989, p. 171-172). Simondon, ao contrário, parte de uma concepção processual das realidades física, biológica, psíquica e coletiva, para explicar a gênese dos objetos técnicos, pois "[é] preciso dirigir-se a uma interpretação genética generalizada das relaçóes entre humano e mundo para apreender a importância filosófica da existência dos objetos técnicos." (SIMONDON 1989, p. 155).

Essa "interpretação genética generalizada" corresponde ao princípio de individuação, modo através do qual a gênese dos seres é compreendida por Simondon. Tal como apresentado por esse autor, em l'Individuation à lumière des notions de forme et d'information, o processo de individuação é uma transdução: estruturação que se propaga, pouco a pouco, no interior de um campo. Partindo da mais simples delas, a transduçáo física, o autor aplica o mesmo princípio de individuação a outros três regimes: biológico, psíquico e coletivo, aos quais correspondem transduçóes biológica, psíquica e coletiva ou transindividual.

Cada uma delas resulta da resolução de tensôes pré-individuais presentes num meio anterior. Desse modo, a transdução em um meio físico dá suporte à próxima operação em meio biológico, assim como esta para o meio psíquico, que, por sua vez, serve de base estruturante para a individuação coletiva. Contudo, não se trata de um esquema hierarquizado, pois uma individuação coletiva pode estruturar tensôes físicas, biológicas, psíquicas e técnicas.

Esse processo se perpetua porque resulta da resolução de tensóes entre cargas de potencial pré-individual, além das estruturaçóes, uma carga de potenciais pré-individuais primordialmente no interior do indivíduo biológico ou ser vivente. No caso específico dos humanos, resta, nas individuações psíquicas, os potenciais que se atualizam através dele em relaçóes transindividuais, colocando-o em relação com outros indivíduos, individuando coletivamente.

Simondon (1989) apresenta de fato suas considerações sobre a individuação técnica, a concretização dos objetos técnicos. Essa individuação específica ocorre por meio da "atividade técnica", a relação desalienada ${ }^{8}$

\footnotetext{
7 "Formado a partir de hylê (matéria) e de morphê (forma), este termo designa a teoria, originalmente aristotélica, que explica a formação do indivíduo pela associação de uma forma e de uma matéria, a forma, ideal (traduzimos igualmente por forma o termo grego eidos), se imprime na matéria concebida como passiva." (COMBES, 1999, p. 8, n.1, traduçáo livre).

8 A alienação técnica é a condição humana causada pela "ausência [da técnica] do mundo das significaçôes e por sua omissão no quadro dos valores e conceitos que participam da cultura”, escreve Simondon (1989, p. 9-10).
} 
através da qual as necessidades do sistema (objeto técnico) são captadas no ato de invençãa e de manutenção.

As reformas de estrutura que permitem ao objeto técnico se especificar constituem o que há de essencial no devir desse objeto; mesmo se as ciências não avancem por certo tempo, o progresso do objeto técnico em direção da especificidade poderá ocorrer; com efeito, o princípio desse progresso é a maneira pela qual, em seu funcionamento e nas reaçóes de seu funcionamento sobre sua utilização, o objeto tem sua causa e condicionamento; o objeto técnico emerso de um trabalho abstrato de organização de subconjuntos é o teatro de relaçôes de causalidades recíprocas. (SIMONDON, 1989, p. 27, tradução livre).

É nessa relação de atividade técnica cuja causa e condição constituem o funcionamento do objeto técnico que o ser humano precisa negociar com as causalidades recíprocas para manter o funcionamento e utilidade do objeto. Este é o esposamento de potenciais psíquicos e físicos que corresponde à estruturação de uma realidade humana e técnica. Porém, essa relação não pode ser restrita à ideia de uma relação individual com o objeto técnico.

Ainda que possam existir atos técnicos individuais, a atividade técnica é tão somente coletiva, porque a reticulação, a qual é a estruturação da realidade técnica, não pode ser produzida por um indivíduo isolado, porque o meio no qual se propaga a estruturação da realidade técnica é definido por seu caráter transcendente e imanente ao indivíduo, diz Simondon (2005); eles são o suporte e o símbolo da relação transindividual - individuação coletiva - (SIMONDON 1989). Assim, o objeto técnico deve ser entendido como uma relação de mediação entre o humano e o mundo, concretizada num artefato individualizado, que corresponde a um estágio genealógico da individuação técnica e coletiva.

A perspectiva relacional sobre o modo de existência dos objetos técnicos nos permite afirmar que "há algo de natureza humana" neles, utilizando um sentido para "natureza" que corresponde a "algo original, anterior à humanidade." (SIMONDON, 1989). Tal passagem pouco intuitiva pode levar a compreensóes confusas sobre a teoria de Simondon. Penso que esmiuçá-la poderá enriquecer a discussão levantada sobre esse trecho específico, na página 9 do texto de Ramos e Fuentes.

Para compreender a ideia referida acima, faz-se necessário considerar que Simondon busca recuperar o significado da palavra natureza como "[...] origem de todas as espécies de ser, [...] anterior a toda individuaçáo" (SIMONDON 2005, p. 305), o que, em outros momentos da obra, é referido 
como pré-individual. Como já dito, a concretização técnica e a individuação coletiva conservam parte da carga pré-individual da tensão estruturante de seus meios. Assim, os objetos técnicos comportam também essa carga de "natureza", ou "apeíron", que é capaz de informar individuaçóes.

Esse argumento auxilia a compreensão do referido trecho de Simondon, citado por Ramos e Fuentes, com o qual se embasa a afirmação de que, para o autor, "o ser humano surge da técnica". Como vemos, na verdade, o objeto técnico é um suporte e símbolo da relação transindividual, da reticulação que informa um coletivo. Em outras palavras, seria antes a sociedade "que surge da técnica" do que o ser humano.

A importância atribuída à individuação técnica respalda o valor cultural da tecnologia, demonstra quão intrincada é a relação entre a humanidade e a tecnicidade, a ponto de não ser possível que compreendêssemos qualquer coletivo humano sem a existência de técnicas. Com isso, percebemos como, para Simondon, a existência de um devir técnico não exclui o humano de seu desígnio, embora - ao negar os pressupostos hilemorfistas - o papel diretivo do humano seja deslocado para uma participação relacional em um processo de individuação coletiva.

Em conclusão, ainda que a técnica tenha um devir próprio na filosofia de Simondon, isso não implica que ela seja capaz de gerar um mundo exterior ao humano. Ela participa da gênese do ser humano como ser social, antes de constituir uma ameaça.

\section{REFERÊNCIAS}

COMBES, Muriel. Simondon individu et collectivité: pour une philosophie du transindividuel. Paris: Presses Universitaires de France, 1999.

SIMONDON, Gilbert. Lindividuation à lá lumière des notions de forme e et d'infomacion. Grenoble, França: Millon, 2005.

SIMONDON, Gilbert. Du mode d'existence des objects techniques. Paris: Aubier, 1989.

SOUZA, E. A. On the philosophical relevance of the miracle argument. Trans/form/ação, Marília, v. 42, n. 4, p. 47-80, Out./Dez., 2019. 